\title{
Consequential late effects after radiotherapy for prostate cancer - a prospective longitudinal quality of life study
}

\author{
Michael Pinkawa*, Richard Holy, Marc D Piroth, Karin Fischedick, Sandra Schaar, Dalma Székely-Orbán, \\ Michael J Eble
}

\begin{abstract}
Background: To answer the question if and to which extent acute symptoms at the end and/or several weeks after radiotherapy can predict adverse urinary and gastrointestinal long-term quality of life (QoL).

Methods: A group of 298 patients has been surveyed prospectively before (time A), at the last day (B), two months after (C) and >one year after (D) radiotherapy using a validated questionnaire (Expanded Prostate Cancer Index Composite). A subgroup of $10 \%$ with the greatest urinary/bowel bother score decrease at time D was defined as patients with adverse long-term QoL.

Results: Subgroup and correlation analyses could demonstrate a strong dependence of urinary/bowel QoL after radiotherapy on urinary/bowel QoL before radiotherapy. In contrast to absolute scores, QoL score changes (relative to baseline scores) did not correlate with pretreatment scores. Long-term changes could be well predicted by acute changes. Patients reporting great/moderate bother with urinary/bowel problems at time $\mathrm{C}$ reported to have great/moderate bother at time $D$ in $\geq 50 \%$, respectively. In a multivariate analysis of factors for adverse long-term urinary and bowel QoL, score changes at time $C$ were found to be independent predictors, respectively. Additionally, QoL changes at time B were independently predictive for adverse long-term bowel QoL.

Conclusions: Consequential late effects play a major role after radiotherapy for prostate cancer. Patients with greater and particularly longer non-healing acute toxicity are candidates for closer follow-up and possible prophylactic actions to reduce a high probability of long-term problems.
\end{abstract}

\section{Background}

External beam radiotherapy is a well established curative treatment for localized prostate cancer [1]. Acute and late toxicity rates after radiotherapy can be considerable and have been subject of many studies. Dose-volume effect relationships have been described extensively [2-6]. Dose escalation studies support the benefit of a dose escalation to total doses approaching 80 Gy concerning the biochemical tumour control or disease-specific survival [7-9]. Subgroups of patients - especially patients with low initial PSA levels $<10 \mathrm{ng} / \mathrm{ml}$ [8] or $<15$ $\mathrm{ng} / \mathrm{ml}$ [7] or low-risk patients [9] - have not been convincingly shown to benefit from total doses $>70 \mathrm{~Gy}$.

\footnotetext{
* Correspondence: mpinkawa@ukaachen.de

* Correspondence: mpinkawa@ukaachen.de 30, 52072 Aachen, Germany
}

(C) 2010 Pinkawa et al; licensee BioMed Central Ltd. This is an Open Access article distributed under the terms of the Creative Commons Attribution License (http://creativecommons.org/licenses/by/2.0), which permits unrestricted use, distribution, and reproduction in any medium, provided the original work is properly cited.

Dose escalation was also associated with a significant increase in late gastrointestinal toxicity $[9,10]$.

In the early years of radiotherapy, the "skin erythema dose" was used for the definition of tolerable doses. During subsequent years, it was realized that no relationship between acute reactions to radiation exposure and late sequelae in other organs and tissues could be established in the majority of patients. More aggressive radiotherapy protocols can result in aggravation, i.e. an increase in severity and duration, of acute radiation effects. Particularly in those organ systems in which a barrier against mechanical and/or chemical stress is established by the acutely responding component - a non-healing acute response can directly progress into a late effect. This phenomenon has been termed a consequential late effect [11]. 
Consequential late effects have also been reported for prostate cancer patients [12,13]. However, though quality of life (QoL) issues are increasingly addressed in the literature [14-17], the impact of acute on late QoL changes has not been analyzed before.

The aim of this study was to answer the question if and to which extent acute symptoms at the end and/or several weeks after radiotherapy can predict adverse urinary and gastrointestinal long-term quality of life (QoL). Patients responded to a QoL questionnaire before, at the last day, two months (median time) after and more than one year after treatment. QoL score changes in the urinary and bowel domain relative to the baseline scores before treatments indicated the extent of QoL impairment.

\section{Methods}

This study was based on consecutive patients who were treated due to localized T1-3N0M0 prostatic carcinoma with three-dimensional conformal radiotherapy in the years 2003-2007. Treatment plans were calculated using a four-field box technique with $15 \mathrm{MeV}$ photons and a multileaf collimator, as reported recently in detail [17]. A margin of $1.5 \mathrm{~cm}$ in the anterior/lateral and $1 \mathrm{~cm}$ in the craniocaudal and dorsal directions to the CTV (prostate with or without seminal vesicles) was applied to define the PTV. The total dose to the prostate in the reference point was 70.2 or $72 \mathrm{~Gy}$ at 1.8 or $2.0 \mathrm{~Gy}$ daily fractions. The integral dose (AUC-area under the curve) was defined as the relation of the area under the dose-volume histogram curve to the total area, multiplied by 100 .

An initial group of 324 patients has been surveyed prospectively before (time A), at the last day (B), two months (median, range 6 weeks- 6 months, $71 \%$ within 9 weeks) after $(\mathrm{C})$ and sixteen months (median, range 1220 months) after (D) radiotherapy using a validated questionnaire, the Expanded Prostate Cancer Index Composite (EPIC) $[18,19]$. The questionnaire comprises 50 items concerning the urinary, bowel, sexual and hormonal domains for function and bothersomeness. Only patients with questionnaire results from both time A and time D have been included in the analysis (92\% of the initial group), resulting in 298 (A), 213 (B), 267 (C) and 298 (D) questionnaires at the respective points in time. The multi-item scale scores were transformed lineary to a 0-100 scale, with higher scores representing better health-related quality of life (QoL). In accordance with data in the literature, mean QoL changes of below 5 points can be defined as clinically not significant, 5-10 as "little" changes, 10-20 as "moderate" changes and $>20$ as "very much" changes $[20,21]$.

The questionnaire was handed over to the patients personally by one of the physicians at time A, B and C.
Patients presented in the department six to ten weeks after the end of treatment. Missed questionnaires in the acute phase (time C) and questionnaires one to two years after radiotherapy (time D) were sent to the patients with a return envelope. If a questionnaire was not returned within four weeks, patients were contacted by telephone and urged to complete it.

Those $10 \%$ of patients who reported the greatest adverse changes of urinary or bowel bother scores (implicating 7 items, respectively) at time D were in a particular focus of this study. They were defined as patients with adverse long-term urinary or bowel QoL. To evaluate the impact of pretreatment scores on posttreatment scores, patients were divided into quartiles in dependence on their pretreatment urinary or bowel bother scores. Patients with the best pretreatment QoL were subsumed in an upper quartile (those $25 \%$ of patients with the highest scores), patients with the worst pretreatment QoL in a lower quartile (those $25 \%$ of patients with the highest scores), remaining patients in the medial quarters.

Sexual and hormonal domains were not considered in this evaluation. As previously demonstrated, sexual function does usually not recover after a decline in the acute phase [22], whereas the hormonal domain cannot be regarded as a domain with major effects from the local radiotherapy treatment.

Statistical analysis was performed using the SPSS 17.0 (SPSS, Chicago, Ill), software. The Wilcoxon's matchedpairs test was applied to determine longitudinal changes in specific subgroups of patients. To explore statistical QoL score differences between different subgroups at a specific time, the Mann-Whitney-U-test was used. Contingency table analysis with the chi-square test was performed to compare treatment groups with respect to categorical variables. To assess the correlation between different scores or score changes, Spearman's rho was determined (correlation coefficient $>0.4$ considered as a relevant correlation). In a forward stepwise univariate and multivariate analysis, pretreatment scores and score changes were tested for their impact on adverse longterm urinary or bowel QoL. All p-values reported are two-sided, $\mathrm{p}<0.05$ is considered significant.

\section{Results}

The median patient age was $71(45-84)$ years. Patients could be classified as low risk (PSA $\leq 10 \mathrm{ng} / \mathrm{ml}$; Gleason score $<7$; clinical $\mathrm{T}$-stage $\leq 2 \mathrm{a}$ ), intermediate risk (PSA $10-20 \mathrm{ng} / \mathrm{ml}$ or Gleason score $=7$ or clinical T-stage $2 \mathrm{~b}-\mathrm{c}$ ) and high risk (two risk factors for intermediate risk or PSA $>20 \mathrm{ng} / \mathrm{ml}$ or Gleason score $>7$ or clinical T-stage $>2 \mathrm{c}$ ) patients in $37 \%, 35 \%$ and $28 \%$, respectively.

Focusing on the dependence of posttreatment scores from pretreatment scores, a different course of urinary 
and bowel bother scores could be clearly demonstrated (Figure 1). Patients with the worst - medial - best pretreatment urinary bother scores improved - remained stable - worsened significantly at times C and D. Scores at time $\mathrm{C}$ were nearly identical as the scores at time $\mathrm{D}$. In the bowel domain, the scores improved significantly between times $B$ and $C$ in every subgroup, comparably to the urinary domain. A further improvement between times $C$ and $D$ was noticed in the subgroups with medial and best pretreatment bowel bother scores. Relative to baseline levels, mean scores of all subgroups decreased at time $\mathrm{D}$ in the range of 6-7 points.
Treatment-related characteristics (fraction dose, total dose, prostate volume, PTV, AUC for bladder and rectum, organ volumes within any of the isodoses $10-100 \%$, percentage of patients with neoadjuvant hormonal therapy) did not differ significantly for the patients who were selected as patients with adverse long-term urinary or bowel QoL in comparison to other patients (Table 1). Looking at the prior scores of these patients, only small differences could be seen before treatment (Figure 2). Urinary bother scores were diverging clearly at time C, in contrast to a divergence of bowel bother scores already at time B.

A)

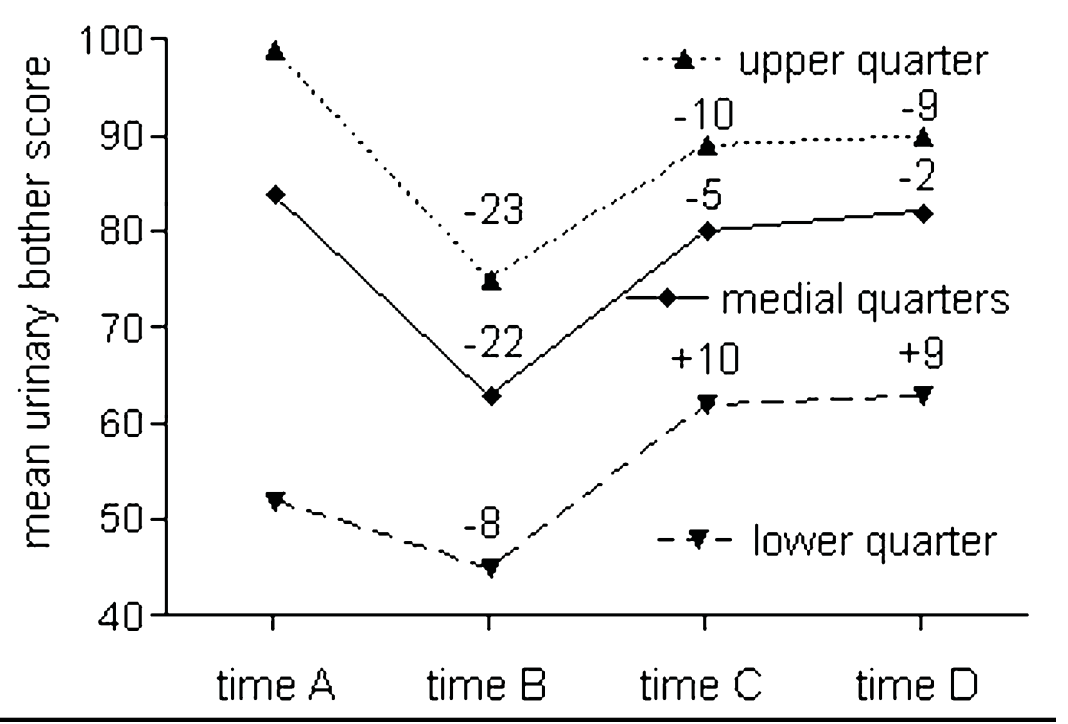

B)

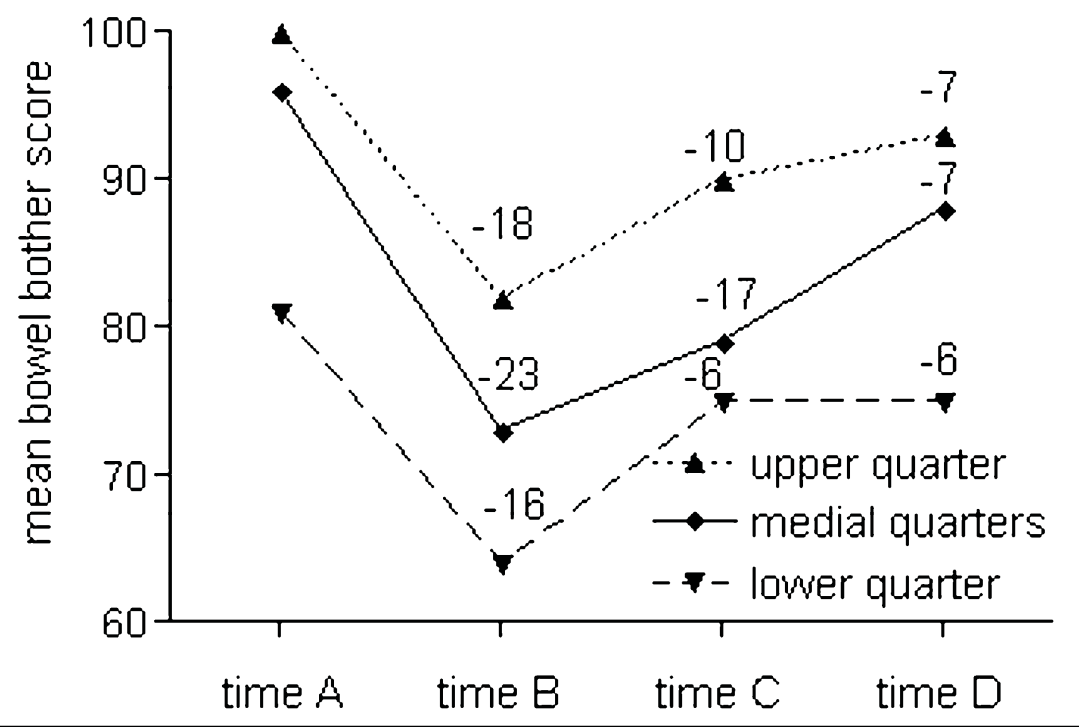

Figure 1 Mean urinary (A) and bowel (B) bother scores in dependence on the baseline scores. A: Baseline score for lower quarter: $<70$; medial quarter: 70-95; upper quarter: $>95$. All changes statistically significant $(p<0.05)$, except changes at time $D$ for patients in the medial quarter. B: Baseline score for lower quarter: <93; medial quarter: 93-99; upper quarter: 100. All changes statistically significant $(p<0.05)$. 
Table 1 Demographic and treatment-related characteristics of patients with vs. without adverse long-term quality of life (QoL) scores

\begin{tabular}{|c|c|c|c|c|}
\hline & \multicolumn{2}{|c|}{ adverse long-term urinary QoL } & \multicolumn{2}{|c|}{ adverse long-term bowel QoL } \\
\hline & yes $(n=261)$ & no $(n=35)$ & yes $(n=264)$ & no $(n=32)$ \\
\hline $\begin{array}{l}\text { patient age/years } \\
\text { median (range) }\end{array}$ & $72(51-83)$ & $71(45-84)$ & $71(51-82)$ & $72(45-84)$ \\
\hline$\%$ fraction dose $1.8 \mathrm{~Gy}$ & $69 \%$ & $72 \%$ & $72 \%$ & $72 \%$ \\
\hline$\%$ total dose $72 \mathrm{~Gy}$ & $54 \%$ & $56 \%$ & $59 \%$ & $55 \%$ \\
\hline $\begin{array}{l}\text { prostate volume/cc } \\
\text { median (range) }\end{array}$ & $40(18-107)$ & $39(11-151)$ & $36(14-107)$ & $40(11-151)$ \\
\hline$\% \mathrm{NHT}$ & $34 \%$ & $32 \%$ & $38 \%$ & $32 \%$ \\
\hline $\begin{array}{l}\text { PTV/cc } \\
\text { median (range) }\end{array}$ & $338(212-529)$ & $330(169-631)$ & $339(117-517)$ & $330(177-517)$ \\
\hline $\begin{array}{l}\text { bladder volume/cc } \\
\text { median (range) }\end{array}$ & $220(54-657)$ & $192(14-806)$ & $181(82-657)$ & $194(14-806)$ \\
\hline $\begin{array}{l}\text { rectum volume/cc } \\
\text { median (range) }\end{array}$ & $102(43-295)$ & $97(28-401)$ & $93(38-295)$ & $98(28-401)$ \\
\hline $\begin{array}{l}\text { AUC for bladder/\% } \\
\text { median (range) }\end{array}$ & $37(12-69)$ & $41(7-98)$ & $35(7-78)$ & $41(7-98)$ \\
\hline bladder volume within $90 \%$ isodose*/\% & $20(5-46)$ & $21(2-64)$ & $20(3-54)$ & $22(2-57)$ \\
\hline $\begin{array}{l}\text { AUC for rectum/\% } \\
\text { median (range) }\end{array}$ & $52(33-77)$ & $51(19-84)$ & $47(23-70)$ & $52(19-84)$ \\
\hline rectum volume within $90 \%$ isodose*/\% & $27(6-64)$ & $28(6-60)$ & $24(12-50)$ & $28(6-64)$ \\
\hline
\end{tabular}

${ }^{*} 100 \%$ = prescription dose of $70.2-72 \mathrm{~Gy} ; 90 \%=63.2-64.8 \mathrm{~Gy}$

Focusing on great/moderate bother from particular problems (specific items of the questionnaire), we found a missing dependence from pretreatment symptoms, and the strongest dependence from symptoms several weeks after radiotherapy (Table 2). Patients reporting great/moderate bother with urinary/bowel problems at time $\mathrm{C}$ reported to have great/moderate bother at time $\mathrm{D}$ in $\geq 50 \%$, respectively. Only $\leq 7 \%$ of patients without great/moderate bother with urinary/bowel problems at time $\mathrm{C}$ reported to have great/moderate bother at time D.

Defining bother score decreases $>20$ points as severe changes, patients with vs. without severe urinary QoL changes at times $B$ and $C$ were found to also have severe urinary QoL changes at time D in $14 \%$ vs. $6 \%$ $(\mathrm{p}=0.042)$ and $40 \%$ vs. $7 \%(\mathrm{p}<0.001)$. Patients with vs. without severe bowel QoL changes at times B and $\mathrm{C}$ were found to also have severe bowel QoL changes at time $\mathrm{D}$ in $30 \%$ vs. $7 \%(\mathrm{p}<0.001)$ and $49 \%$ vs. $7 \%$ $(\mathrm{p}<0.001)$.

Correlating absolute urinary and bowel scores at different intervals, good intra- and interdomain correlations of urinary and bowel scores became evident - with higher correlation indices after than before radiotherapy. A strong correlation between scores at different intervals within a specific domain resulted (Table 3). Considering pretreatment urinary/bowel QoL scores and QoL score changes relative to baseline scores at times $\mathrm{B}, \mathrm{C}$ and $\mathrm{D}$, the highest correlation coefficients were found between changes at times $\mathrm{C}$ and $\mathrm{D}(\mathrm{r}>0.5 ; \mathrm{p}<0.001)$, respectively (Table 4 , pretreatment scores not shown due to low correlation coefficients $r<0.4$ ).

In a univariate analysis of factors for adverse longterm urinary and bowel QoL (Table 5), various factors were found to significantly predict adverse long-term QoL - including crossover relations between the urinary and bowel domains. Patients with adverse long-term urinary QoL were more likely to have adverse long-term bowel QoL and vice versa (patients with vs. without adverse urinary QoL reported a mean bowel score decrease of 21 vs. 5 points at time D; $\mathrm{p}<0.001$; patients with vs. without adverse bowel QoL reported a mean urinary score decrease of 16 vs. -1 points at time $\mathrm{D} ; \mathrm{p}<0.001$ ).

The multivariate analysis was performed to demonstrate independent factors - intradomain score changes relative to baseline at time $\mathrm{C}$ proved to be independent significant predictors for adverse score changes at time $\mathrm{D}$, respectively. Additionally, bowel QoL changes at time $B$ were independently predictive for adverse long-term bowel QoL (Table 5).

\section{Discussion}

In this study, we could demonstrate the strong influence of acute side effects on long-term toxicity in prostate cancer treatment. In contrast to studies in the past, based on a grading system $[12,13]$, a quality of life analysis was used to elaborate the impact of consequential 
A)

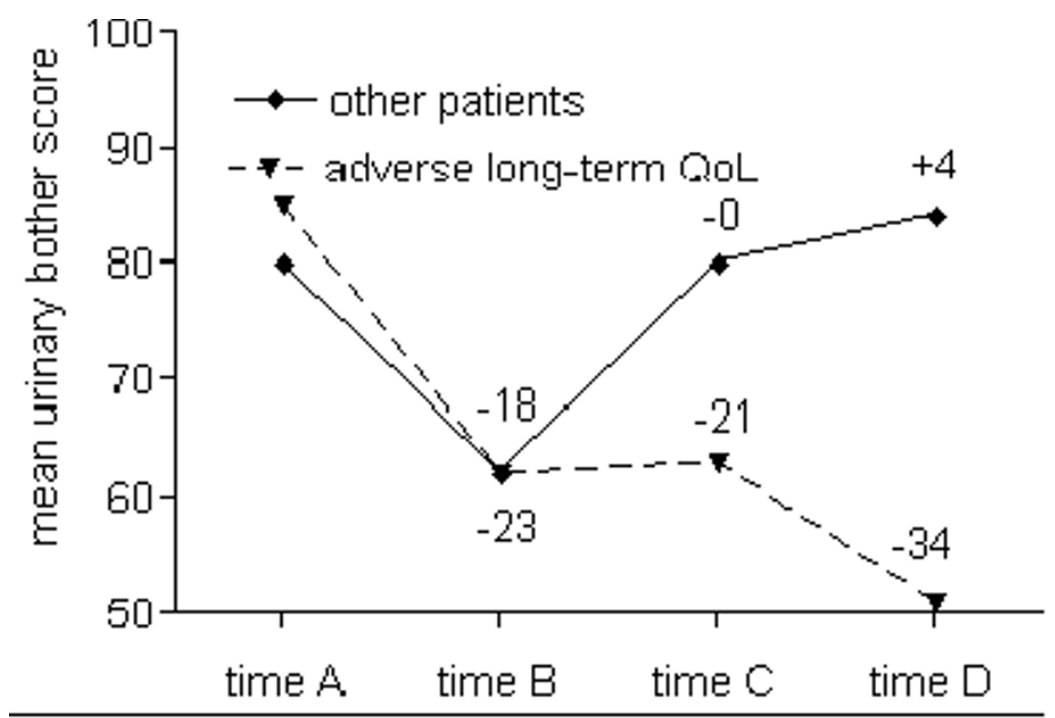

B)

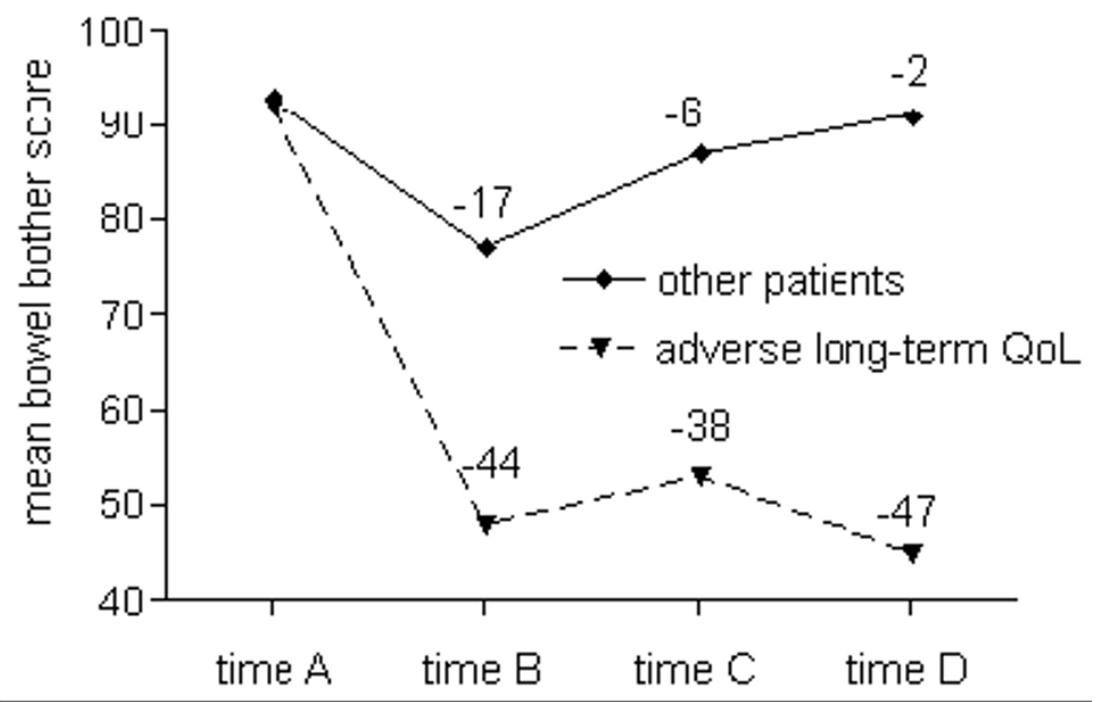

Figure 2 Mean urinary (A) and bowel (B) bother scores for patients with vs. without adverse long-term urinary quality of life (QoL).

late effects on long-term quality of life. EPIC questionnaire measurements have the advantage of being more sensitive to changes in acute bowel toxicity in comparison to RTOG acute morbidity scoring criteria or proctoscopic toxicity scores [23]. Apparently, prostate cancer radiotherapy with doses $>70$ Gy can lead to a relevant severity and duration of acute radiation effects. The intestinal or bladder mucosa is damaged to a considerable degree, so that an adequate barrier against mechanical and/or chemical stress is not present any more for a considerable period of time. The non-healing response can progress directly into a late effect. In contrast to a low percentage of patients (5-7\%) who assess their urinary function or bowel habits to be a great or moderate problem more than a year after radiotherapy without the same assessment already several weeks after radiotherapy, $\geq 50 \%$ who reported one of these problems several weeks after radiotherapy still had the same bother more than a year after radiotherapy, respectively.

Urinary and bowel QoL after radiotherapy was found to be strongly dependent on urinary and bowel QoL before radiotherapy. Nevertheless, a difference was found between urinary and bowel QoL. Acute bowel problems were gradually improving over time. In comparison to baseline, scores at time D decreased 6-7 points for all subgroups. In contrast to bowel bother scores, no further improvement was noticed for urinary bother scores between time C and D. Significantly lower scores at times 
Table 2 Percentage of patients reporting certain long-term bother (time D) in dependence on pretreatment (time A) or acute (time $B$ and $C$ ) bother

\begin{tabular}{|c|c|c|c|}
\hline \multirow[b]{2}{*}{ great/moderate bother with: } & \multicolumn{3}{|c|}{$\begin{array}{l}\text { probability of long-term bother at time } D \\
\text { if bother already present vs. absent at time } A / B / C \text { [p-value] }\end{array}$} \\
\hline & time $A$ & time $B$ & time $\mathrm{C}$ \\
\hline dripping or leaking urine & $\begin{array}{l}6 \% \text { vs. } 8 \% \\
\text { n.s. }\end{array}$ & $\begin{array}{l}19 \% \text { vs. } 3 \% \\
{[0.001]}\end{array}$ & $\begin{array}{l}50 \% \text { vs. } 3 \% \\
\quad[<0.001]\end{array}$ \\
\hline pain or burning on urination & $\begin{array}{l}0 \% \text { vs. } 6 \% \\
\text { n.s. }\end{array}$ & $\begin{array}{l}11 \% \text { vs. } 1 \% \\
{[0.001]}\end{array}$ & $\begin{array}{l}28 \% \text { vs. } 3 \% \\
{[<0.001]}\end{array}$ \\
\hline waking up to urinate & $\begin{array}{l}26 \% \text { vs. } 29 \% \\
\text { n.s. }\end{array}$ & $\begin{array}{l}44 \% \text { vs. } 8 \% \\
{[<0.001]}\end{array}$ & $\begin{array}{l}72 \% \text { vs. } 13 \% \\
\quad[<0.001]\end{array}$ \\
\hline urinary function overall & $\begin{array}{l}7 \% \text { vs. } 16 \% \\
\text { n.s. }\end{array}$ & $\begin{array}{l}24 \% \text { vs. } 5 \% \\
{[<0.001]}\end{array}$ & $\begin{array}{l}50 \% \text { vs. } 7 \% \\
{[<0.001]}\end{array}$ \\
\hline urgency to have a bowel movement & $\begin{array}{l}21 \% \text { vs. } 13 \% \\
\text { n.s. }\end{array}$ & $\begin{array}{c}25 \% \text { vs. } 5 \% \\
{[<0.001]}\end{array}$ & $\begin{array}{c}50 \% \text { vs. } 6 \% \\
{[<0.001]}\end{array}$ \\
\hline losing control of stools & $\begin{array}{c}25 \% \text { vs. } 5 \% \\
\text { n.s. }\end{array}$ & $\begin{array}{c}25 \% \text { vs. } 1 \% \\
{[<0.001]}\end{array}$ & $\begin{array}{c}45 \% \text { vs. } 3 \% \\
{[<0.001]}\end{array}$ \\
\hline bloody stools & - vs. $3 \%^{*}$ & $\begin{array}{c}0 \% \text { vs. } 3 \% \\
\text { n.s. }\end{array}$ & $\begin{array}{c}33 \% \text { vs. } 2 \% \\
{[<0.001]}\end{array}$ \\
\hline bowel habits overall & $\begin{array}{c}28 \% \text { vs. } 13 \% \\
\text { n.s. }\end{array}$ & $\begin{array}{c}34 \% \text { vs. } 3 \% \\
{[<0.001]}\end{array}$ & $\begin{array}{c}56 \% \text { vs. } 5 \% \\
{[<0.001]}\end{array}$ \\
\hline
\end{tabular}

Example: $56 \%$ of patients with great/moderate bother with bowel habits overall at time C report the same bother at time D; $5 \%$ of patients without great/ moderate bother with bowel habits overall at time $C$ report this bother at time $D$

n.s. $=$ not significant

*no patients with great/moderate bother with bloody stools at time $\mathrm{A}$

Table 3 Spearman's correlation index between quality of life scores (only indices $r>0.4$ shown; $p<0.001$ for all)

\begin{tabular}{lcccccccc}
\hline & UBS time A & BBS time A & UBS time B & BBS time B & UBS time C & BBS time C & UBS time D & BBS time D \\
\hline UBS time A & & 0.43 & 0.54 & - & 0.56 & - & - & 0.55 \\
\hline BBS time A & 0.43 & & - & - & - & - & - & 0.48 \\
\hline UBS time B & 0.54 & - & & 0.54 & 0.64 & - & 0.56 & - \\
\hline BBS time B & - & - & 0.54 & & 0.42 & 0.63 & 0.41 & 0.50 \\
\hline UBS time C & 0.56 & - & 0.64 & 0.42 & & 0.53 & 0.46 & 0.57 \\
\hline BBS time C & - & - & - & 0.63 & 0.53 & & 0.46 & 0.54 \\
\hline UBS time D & 0.55 & - & 0.56 & 0.41 & 0.69 & -57 & 0.54 \\
\hline BBS time D & - & 0.48 & - & 0.50 & - & 0.57 & \\
\hline
\end{tabular}

Abbreviations: UBS = urinary bother score; $\mathrm{BBS}=$ bowel bother score

Table 4 Spearman's correlation index between quality of life score changes relative to baseline scores at time A (only indices $r>0.4$ shown; $p<0.001$ for all)

UBS change BBS change time $B$ UBS change time $C$ BBS change time $C$ UBS change time $D$ BBS change time $D$ time B

\begin{tabular}{lcccccc}
\hline UBS change time B & & 0.45 & 0.51 & - & - & - \\
\hline BBS change time B & 0.45 & & - & 0.53 & - & - \\
\hline UBS change time C & 0.51 & - & - & - & - & - \\
\hline BBS change time C & - & 0.53 & - & & -52 \\
\hline
\end{tabular}

Abbreviations: UBS = urinary bother score; BBS = bowel bother score

$\mathrm{C}$ and D in comparison to baseline were only found for the patients with the best baseline scores. Urinary QoL for the patients with initially very low scores improved significantly, suggesting a possible effect of radiotherapy on the reduction of benign prostatic hyperplasia. Long-term urinary and bowel scores at time D were correlating well with the respective scores at time A - but also B and C. Correlation indices were gradually improving over time, so that the best correlation was found between the respective scores at times $\mathrm{C}$ and $\mathrm{D}$ (Table 3 ).

A different aspect (main aspect) of this study is the evaluation of QoL score changes relative to baseline 
Table 5 Predictive factors for low long-term quality of life (QoL) in univariate and multivariate analysis (urinary and bowel bother scores at time $\mathrm{A}$ and score changes relative to baseline scores at times $\mathrm{B}$ and $\mathrm{C}$ were tested; significant factors are presented)

\begin{tabular}{|c|c|c|c|c|c|}
\hline \multirow[b]{2}{*}{ item } & \multirow[b]{2}{*}{ risk factor } & \multicolumn{2}{|c|}{ univariate analysis } & \multicolumn{2}{|c|}{ multivariate analysis } \\
\hline & & $\begin{array}{c}\text { hazard ratio } \\
{[95 \% \mathrm{Cl}]}\end{array}$ & p-value & $\begin{array}{c}\text { hazard ratio } \\
{[95 \% \mathrm{Cl}]}\end{array}$ & p-value \\
\hline \multirow[t]{4}{*}{ low long-term urinary QoL } & urinary bother score at time $B$ & $\begin{array}{c}1.03 \\
{[1.00-1.05]}\end{array}$ & 0.032 & - & - \\
\hline & urinary bother score change at time $\mathrm{C}$ & $\begin{array}{c}1.06 \\
{[1.04-1.08]}\end{array}$ & $<0.001$ & $\begin{array}{c}1.06 \\
{[1.04-1.08]}\end{array}$ & $<0.001$ \\
\hline & bowel bother score at time $\mathrm{A}$ & $\begin{array}{c}1.03 \\
{[1.00-1.05]}\end{array}$ & 0.028 & - & - \\
\hline & bowel bother score change at time $C$ & $\begin{array}{c}1.03 \\
{[1.01-1.04]}\end{array}$ & 0.002 & - & - \\
\hline \multirow[t]{4}{*}{ low long-term bowel QoL } & urinary bother score change at time B & $\begin{array}{c}1.02 \\
{[1.00-1.04]}\end{array}$ & 0.048 & - & - \\
\hline & urinary bother score change at time $C$ & $\begin{array}{c}1.02 \\
{[1.00-1.04]}\end{array}$ & 0.031 & - & - \\
\hline & bowel bother score change at time B & $\begin{array}{c}1.05 \\
{[1.03-1.08]}\end{array}$ & $<0.001$ & $\begin{array}{c}1.03 \\
{[1.00-1.06]}\end{array}$ & 0.049 \\
\hline & bowel bother score change at time $C$ & $\begin{array}{c}1.06 \\
{[1.04-1.08]}\end{array}$ & $<0.001$ & $\begin{array}{c}1.05 \\
{[1.02-1.08]}\end{array}$ & $<0.001$ \\
\hline
\end{tabular}

scores before treatment. In contrast to an absolute QoL level, adverse changes imply radiotherapy toxicity impossible to assess with a single measurement after radiotherapy. In contrast to absolute scores, QoL score changes were not correlating with pretreatment scores. In respect of long-term scores, the best predictive value (greatest correlation index) was found for scores at time $C$, i.e. in case of considerable acute changes several weeks after treatment, comparable changes can still be expected more than one year after treatment.

Finally, we have focused on the patients with the greatest long-term QoL impairment relative to baseline scores. We could exclude a significant impact of treatmentrelated characteristics on this impairment for this particular patient group - not implying that these characteristics do not have any meaning for radiotherapy-related toxicity. As reported in the already published studies, factors like bladder volume, prostate volume or hormonal therapy have certainly an influence on particular problems [4,21]. A particular aspect of this evaluation is a homogenous treatment of the total study group concerning the technique, planning target volume definition and dose prescription. In most other study populations, patients with various techniques and total doses are combined $[1,3,12,13,24]$. The significant impact of dose to critical structures on toxicity could be demonstrated in these studies with different dose levels. This correlation could not be shown in our homogenous study population (all patients treated with the same technique to a dose of 70.2-72 Gy). We have to be aware that the dose-volume histogram is related to a single treatment planning CT scan. Taking into account changing organ volumes during the treatment $[25,26]$, it might not be sensitive enough to discriminate clearly between patients with higher or lower volumes within certain dose levels over the entire treatment (all individual fractions).

Considering QoL scores of patients with the greatest long-term impairment in comparison to other patients (Figure 2), differences of QoL scores became well evident with time. A considerable divergence of urinary scores resulted at time $C$ : patients with adverse longterm QoL were not able to recover from their acute symptoms - in contrast to a complete recovery for other patients. The impact of consequential late effects is demonstrated clearly in these curves. Patients with consequential late effects were not able to repair the acute tissue damage and QoL decreased even more with time. In contrast to the urinary domain, a drastic divergence of bowel bother scores resulted already at time B. A similar progression followed: patients with adverse longterm QoL were not able to repair the damage, while other patients (nearly) returned to their baseline levels before radiotherapy. The multivariate analysis supports well the results of these curves: urinary bother score changes at time $\mathrm{C}$ were highly predictive of adverse long-term urinary QoL; bowel bother score changes at times $\mathrm{B}$ and $\mathrm{C}$ were independently predictive for adverse long-term bowel QoL.

Urinary and bowel score changes at time $C$ have been shown to predict both adverse urinary and bowel longterm QoL in univariate analysis. The interdomain predictions were not independent from the respective other 
domain, i.e. they were not independent factors in the multivariate analysis. An individual radiosensitivity is suggested by these data: patients with reduced repair capacity of the bladder wall or urethra are more likely to have a reduced repair capacity of the rectal wall and vice versa.

The results of this study emphasize the need of close follow-up and early prophylactic actions for patients with greater and longer acute radiotherapy-associated toxicities to possibly prevent late toxicities, though these possibilities are currently limited. The time to filter candidates for these actions can be two months after radiotherapy (median time of time $\mathrm{C}$ questionnaire) concerning urinary problems and the end of radiotherapy concerning bowel problems. Taking into account the well known association of dose with late toxicity $[8,10]$, stopping the radiation treatment at a lower dose (for example $70 \mathrm{~Gy}$ instead of $80 \mathrm{~Gy}$ ) might be advisable for selected patients (for example older low-risk patients with limited life expectancy and only questionable benefit of a dose escalation) with heavy acute bowel toxicity. This concept is currently not accepted. The decision for a dose prescription is independent from the severity of acute effects.

There are no standard prophylactic regimens to ameliorate urinary symptoms after external beam radiotherapy. After prostate brachytherapy - known to be associated with greater urinary morbidity in comparison to external beam radiotherapy - alpha-blockers are commonly administered. The beneficial effect on urinary symptoms has been shown in a placebo-controlled randomized study [27]. An advantage might also be possible for patients after external beam radiotherapy.

Patients with greater and longer acute rectal morbidity should be advised to avoid unnecessary mechanical rectal wall irritation - a low residue diet, reducing the frequency and volume of stools might be beneficial in this context. Constipation should be treated with adequate dietary measures or laxatives.

Medical treatment with anti-inflammatory drugs, like corticosteroids or mesalamine, can reduce acute inflammatory symptoms. However, a long-term effect could not be demonstrated in the past [28]. Anti-inflammatory drugs are inhibiting protein synthesis, so that tissue repair might even be impaired. Other drugs, like retinal palmitate (vitamin A) might more effectively promote wound healing [29]. Patients with acute bowel problems should in any case be specifically informed to avoid invasive procedures and biopsies of the rectal wall. Biopsy may cause persistent inflammation, decrease healing, and precipitate fistula formation [30].

\section{Conclusions}

In contrast to absolute scores after radiotherapy, quality of life changes cannot be predicted by pretreatment scores. Consequential late effects play a major role after radiotherapy for prostate cancer. Long-term gastrointestinal symptoms are well predicted by symptoms at the end of and several weeks after treatment, suggesting an inefficiency of the repair system and a non-healing acute response. Urinary symptoms without recovery within a few weeks after radiotherapy are likewise highly predictive for adverse long-term urinary quality of life.

Patients with greater and longer acute toxicity are candidates for closer follow-up and possible prophylactic actions to reduce a high probability of long-term problems, including possibly a total dose reduction for selected patients with particularly bothersome acute gastrointestinal problems.

\section{Acknowledgements}

The study was funded by the research resources of the Department of Radiation Oncology, RWTH Aachen University, Germany. We would like to thank the staff who took care of our patients' needs, and who were involved in gathering, documenting, verifying, forwarding, and processing the clinical data.

\section{Authors' contributions}

MP, MJE have made substantial contributions to conception and design; MP and KF have made substantial contributions to acquisition of data; MP, RH, MDP, KF, SS, DS, MJE to analysis and interpretation of data. MP has been involved in drafting the manuscript. $\mathrm{RH}, \mathrm{MDP}, \mathrm{KF}, \mathrm{SS}, \mathrm{DS}, \mathrm{MJE}$ revised it critically for important intellectual content. All authors have given final approval of the version to be published.

\section{Competing interests}

The authors declare that they have no competing interests.

Received: 25 January 2010 Accepted: 8 April 2010

Published: 8 April 2010

\section{References}

1. Welz S, Nyazi M, Belka C, Ganswindt U: Surgery vs. radiotherapy in localized prostate cancer. Radiat Oncol 2008, 3:23.

2. Cheung R, Tucker SL, Ye JS, Dong L, Liu H, Huang E, Mohan R, Kuban D: Characterization of rectal normal tissue complication probability after high-dose external beam radiotherapy for prostate cancer. Int J Radiat Oncol Biol Phys 2004, 58:1513-1519.

3. Zapatero A, Garcia-Vicente F, Modolell I, Alcantara P, Floriano A, CruzConde A, Torres JJ, Pérez-Torrubia A: Impact of mean rectal dose on late rectal bleeding after conformal radiotherapy for prostate cancer: dosevolume effect. Int J Radiat Oncol Biol Phys 2004, 59:1343-1351.

4. Selek U, Cheung R, Lii M, Allen P, Steadham RE, Vantreese TR Jr, Little DJ, Rosen II, Kuban D: Erectile dysfunction and radiation dose to penile base structures: a lack of correlation. Int J Radiat Oncol Biol Phys 2004, 59:1039-1046.

5. Pinkawa M, Fischedick K, Asadpour B, Gagel B, Piroth MD, Eble MJ: Lowgrade toxicity after conformal radiation therapy for prostate cancer impact of bladder volume. Int J Radiat Oncol Biol Phys 2006, 64:835-841.

6. Michalski JM, Gay H, Jackson A, Tucker SL, Deasy JO: Radiation dosevolume effects in radiation-induced rectal injury. Int J Radiat Oncol Biol Phys 2010, 76:S123-S129.

7. Beckendorf V, Guerif S, Le Prise E, Cosset J, Bougnoux A, Chauvet B, Salem N, Romenstaing P, Luporsi I, Bey P: 70 Gy versus 80 Gy dose escalation getug 06 french trial for localized prostate cancer: mature results. Int J Radiat Oncol Biol Phys 2008, 72:S96-S97.

8. Kuban DA, Tucker SL, Dong L, Starkschall G, Huang EH, Cheung MR, Lee AK, Pollack A: Long-term results of the M.D. Anderson randomized doseescalation trial for prostate cancer. Int J Radiat Oncol Biol Phys 2008, 70:67-74. 
9. Peeters ST, Heemsbergen WD, Koper PC, van Putten WL, Slot A, Dielwart MF, Dielwart MFH, Bonfer JMG, Incrocci L, Lebesque JV: Doseresponse in radiotherapy for localized prostate cancer: results of the Dutch multicenter randomized phase III trial comparing $68 \mathrm{~Gy}$ of radiotherapy with $78 \mathrm{~Gy}$. J Clin Oncol 2006, 24:1990-1996.

10. Al-Mamgani $A$, van Putten WL, Heemsbergen WD, van Leenders GJLH, Slot A, Dielwart MFH, Incrocci L, Lebesque JV: Update of dutch multicenter dose-escalation trial of radiotherapy for localized prostate cancer. Int J Radiat Oncol Biol Phys 2008, 72:980-988.

11. Dörr $\mathrm{W}$, Hendry $\mathrm{JH}$ : Consequential late effects in normal tissues. Radiother Oncol 2001, 61:223-231.

12. Schultheiss TE, Lee WR, Hunt MA, Hanlon AL, Peter RS, Hanks GE: Late GI and GU complications in the treatment of prostate cancer. Int J Radiat Oncol Biol Phys 1997, 37:3-11.

13. Heemsbergen WD, Peeters ST, Koper PC, Hoogeman MS, Lebesque JV: Acute and late gastrointestinal toxicity after radiotherapy in prostate cancer patients: consequential late damage. Int J Radiat Oncol Biol Phys 2006, 66:3-10.

14. Joseph KJ, Alvi R, Skarsgard D, Tonita J, Pervez N, Small C, Tai P: Analysis of health-related quality of life (HRQoL) of patients with clinically localized prostate cancer, one year after treatment with external beam radiotherapy (EBRT) alone versus EBRT and high dose rate brachytherapy (HDRBT). Radiat Oncol 2008, 3:20.

15. Fransson P, Lund J, Damber J, Klepp O, Wiklund F, Fossa S, Widmark A: Quality of life in patients with locally advanced prostate cancer given endocrine treatment with or without radiotherapy; 4-year follow-up of SPCG-7/SFUO-3, an open-label, randomised, phase III trial. Lancet Oncol 2009, 10:370-380.

16. Geinitz H, Thamm R, Scholz C, Heinrich C, Prause N, Kerndl S, Keller M, Busch R, Molls M, Zimmermann FB: Longitudinal analysis of quality of life in patients receiving conformal radiation therapy for prostate cancer. Strahlenther Onkol 2010, 186:46-52.

17. Pinkawa M, Piroth MD, Fischedick K, Nussen S, Klotz J, Holy R, Eble MJ: Selfassessed toxicity after external beam radiotherapy for prostate cancer predictive factors on irritative symptoms, incontinence and rectal bleeding. Radiat Oncol 2009, 4:36.

18. Wei JT, Dunn RL, Litwin MS, Sandler HM, Sanda MG: Development and validation of the expanded prostate cancer index composite (epic) for comprehensive assessment of health-related quality of life in men with prostate cancer. Urology 2000, 56:899-905.

19. Volz-Sidiropoulou E, Pinkawa M, Fischedick K, Jakse G, Gauggel S, Eble MJ: Factor analysis of the Expanded Prostate Cancer Index Composite (EPIC) in a patient group after primary (external beam radiotherapy and permanent iodine-125 brachytherapy) and postoperative radiotherapy for prostate cancer. Curr Urol 2008, 2:122-129.

20. Ososba D, Rodrigues G, Myles J, Zee B, Pater J: Interpreting the significance of changes in health-related quality-of-life scores. J Clin Oncol 1998, 16:139-144.

21. Pinkawa M, Fischedick K, Asadpour B, Gagel B, Piroth MD, Nussen S, Eble MJ: Toxicity profile with a large prostate volume after external beam radiotherapy for localized prostate cancer. Int J Radiat Oncol Biol Phys 2008, 70:83-89.

22. Pinkawa M, Gagel B, Piroth MD, Fischedick K, Asadpour B, Kehl M, Klotz J, Eble MJ: Erectile dysfunction after external beam radiotherapy for prostate cancer. Eur Urol 2009, 55:227-236.

23. Muanza TM, Albert PS, Smith S, Godette D, Crouse NS, Cooley-Zgela T, Scinto L, Camphausen K, Coleman CN, Ménard C: Comparing measures of acute bowel toxicity in patients with prostate cancer treated with external beam radiation therapy. Int J Radiat Oncol Biol Phys 2005, 62:1316-1321.

24. Michalski JM, Winter K, Purdy JA, Parliament M, Wong H, Perez CA, Roach $M$, Bosch W, Cox JD: Toxicity after three-dimensional radiotherapy for prostate cancer on RTOG 9406 dose Level V. Int J Radiat Oncol Biol Phys 2005, 62:706-713.

25. Martin JM, Bayley A, Bristow R, Chung P, Gospodarowicz M, Menard C, Milosevic M, Rosewall T, Wade PR, Catton CN: Image guided dose escalated prostate radiotherapy: still room to improve. Radiat Oncol 2008, 4:50.

26. Pinkawa M, Pursch-Lee M, Asadpour B, Gagel B, Piroth MD, Nussen S, Eble MJ: Image-guided radiotherapy for prostate cancer. Implementation of ultrasound-based prostate localization for the analysis of inter- and intrafractiuon organ motion. Strahlenther Onkol 2008, 184:679-685.

27. Elshaikh MA, Ulchaker JC, Reddy CA, Angermeier KW, Klein EA, Chehade N, Altman A, Ciezki JP: Prophylactic tamsulosin (Flomax) in patients undergoing prostate $125 \mathrm{I}$ brachytherapy for prostate carcinoma: final report of a double-blind placebo-controlled randomized study. Int J Radiat Oncol Biol Phys 2005, 62:164-169.

28. Fantin AC, Binek J, Jabar FM, Meyenberger C: Argon beam coagulation for treatment of symptomatic radiation-induced proctitis. Gastrointest EndosC 1999, 49:515-518.

29. Ehrenpreis ED, Jani A, Levitsky J, Ahn J, Hong J: A prospective, randomized, double-blind, placebo-controlled trial of retinol-palmitate (vitamin A) for symptomatic chronic radiation proctopathy. Dis Colon Rectum 2005, 48:1-8.

30. Tran A, Wallner K, Merrick GS, Seeberger J, Armstrong J, Mueller A, Cavanagh W, Lin D, Butler W: Rectal fistulas following prostate brachytherapy. Int J Radiat Oncol Biol Phys 2005, 63:150-154.

doi:10.1186/1748-717X-5-27

Cite this article as: Pinkawa et al:: Consequential late effects after radiotherapy for prostate cancer - a prospective longitudinal quality of life study. Radiation Oncology 2010 5:27.

\section{Submit your next manuscript to BioMed Central and take full advantage of:}

- Convenient online submission

- Thorough peer review

- No space constraints or color figure charges

- Immediate publication on acceptance

- Inclusion in PubMed, CAS, Scopus and Google Scholar

- Research which is freely available for redistribution

Submit your manuscript at www.biomedcentral.com/submit
Biomed Central 